\title{
Primer septorinoplasti olgusunda rinolit
}

Rhinolithiasis in a primary septorhinoplasty case

\author{
Göksel Turhal Kerem Öztürk Sercan Göde Fazıl Apaydın \\ Ege Üniversitesi Tıp Fakültesi, Kulak Burun Boğaz Hastalıkları Anabilim Dalı, İzmir, Türkiye
}

\section{Öz}

Rinolitler nazal kavitede nadir görülen ve genellikle unilateral, endojen ya da ekzojen bir nidusun çevresinde tuzların birikmesiyle oluşan kitlelerdir. Tipik semptomları tek taraflı burun tıkanıklığı, kötü kokulu pürülan burun akıntı, epistaksis, kabuklanma, burunda ya da yüzde şişlik, anosmi, epifora ve baş ağrısıdır. Tanı anterior rinoskopi, nazal endoskopi ve bilgisayarlı tomografiyle konmaktadır. Bu yazıda herhangi bir şikayeti olmayan ve primer septorinoplasti sırasında rastlantısal olarak saptanan bir rinolit olgusunu bildiriyoruz.

Anahtar Sözcükler: Rinolit, septum deviasyonu, primer septorinoplasti.

\begin{abstract}
Rhinoliths are rare, mostly unilateral masses in the nasal cavity caused by the deposition of salt around an endogenous or exogenous nidus. Typical symptoms are unilateral nasal obstruction, malodorous purulant discharge, epistaxis, crusting, edema on the nose or face, anosmia, epiphora and headache. Diagnosis is made by anterior rhinoscopy, nasal endoscopy or computerized tomography. In this manuscript we report a rhinolithiasis case incidentally found in a primary septorhinoplasty patient without any previous symptoms.
\end{abstract}

Keywords: Rhinolithiasis, septum deviation, primary septorhinoplasty.

\section{Giriş}

Rinolit nazal kavitede bir nidus veya yabancı cisim çevresinde zaman içeresinde tuzların birikmesiyle oluşan kitledir. Rinolitler nadir görülür ve literatürde genellikle olgu sunumları olarak bildirilmiştir. Tipik semptomları tek taraflı burun tıkanıklığı, kötü kokulu pürülan burun akıntı, epistaksis, kabuklanma, burunda ya da yüzde şişlik, anosmi, epifora ve baş ağrısıdır (1). Bazen uzun yıllar belirti vermeyebilir ve rutin muayene sırasında rastlantısal olarak saptanabilir. Olguda ileri derece septum deviasyonu ve eksternal burun deformitesi nedeniyle primer septorinoplasti olan ve operasyon sırasında deviasyonun arkasında rastlantısal olarak saptanan bir rinolit vakası bildirilmiştir.

\section{Olgu Sunumu}

17 yaşında bilinen hiçbir ek hastalığı olmayan bayan hasta burun tıkanıklığı ve şekil bozukluğu şikayetiyle kulak burun boğaz hastalıkları polikliniğine başvurdu. Hastanın muayenesinde septum sola ileri derece deviye izlendi ve nazal aksta $\mathrm{C}$ deformitesi izlendi.

\footnotetext{
Yazışma Adresi: Göksel Turhal

Ege Üniversitesi Tıp Fakültesi, Kulak Burun Boğaz Hastalıkları Anabilim Dalı, İzmir, Türkiye
}

Makalenin Geliş Tarihi: 23.11.2014

Kabul Tarihi: 11.12.2014
Hastanın anamnezinde 7 yaşında travmaya bağlı nazal fraktür öyküsü mevcuttu. Hastaya fonksiyonel septorinoplasti önerilerek kliniğe yatışı yapıldı. Hastanın sol nazal kavitedeki septum deviasyonu rijit ve fleksibl endoskop geçmesine olanak vermeyecek kadar ileri düzeyde izlendi. Açık teknik primer septorinoplasti uygulandı. Operasyon sırasında septumun deviye kısımları çıkarılıp sol nazal pasaj açıldıktan sonra deviasyonun hemen arkasında alt konka ile septum arasında yerleşmiş koyu gri renkli, üzerinde sekresyon ve koagulumlar olan sert, yabancı bir cisim izlendi. Rinolitle uyumlu olan $3 \times 1 \mathrm{~cm}$ uzunluğundaki cisim çıkarıldı ve hastanın primer septorinoplastisi tamamlandı. Nazal mukozada erozyon izlenmedi. Rinolit kırılarak içinde yabancı cisim olup olmadığı araştırıldı (Şekil-1) ancak rinolit içerisinde yabancı cisim izlenmedi.

\section{Tartışma}

Rinolitlerin patogenezi tam olarak aydınlatılamamışsa da genellikle burun içindeki bir yabancı cismin çevresinde mukus ve tuzların birikerek katılaşmasıyla oluştuğu düşünülmekte olup kadınlarda erkeklere göre daha sık görülmektedir (1). Yabancı cisimlerin çoğu ekzojen kaynaklı olmakla birlikte nadir olsa da endojen kaynaklı rinolit de oluşabilmektedir. 


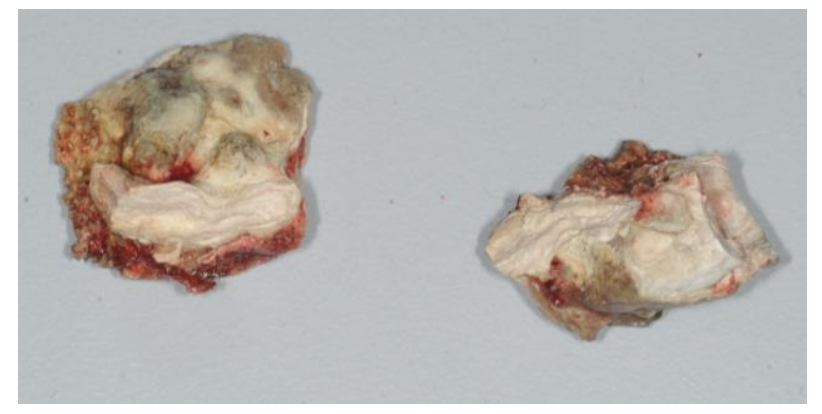

Şekil-1. Rinolitin iki parçaya bölündükten sonraki görünümü.

Boncuk, oyuncak parçaları, taş, meyve çekirdekleri, bezelye, pamuk, tohumlar, fasülye, kağıt, ahşap ya da cam parçaları gibi egzojen ajanlar ya da diş, kemik parçaları, trombüs, kurumuş pürülan sekresyonlar ya da deskuame epitel gibi endojen ajanlar rinolitin kaynağı olabilmektedir $(2,3)$. Yabancı cismin kronik yangısal bir reaksiyon oluşturduğu düşünülmekte ve bunun sonucunda kalsiyum fosfat, kalsiyum karbonat ve magnezyum fosfat gibi mineraller çökmektedir.

En sık görülen şikayet burun tıkanıklığı olmakla birlikte bunun dışında sık görülen şikayetler kötü kokulu pürülan burun akıntı, epistaksis, kabuklanma, burunda ya da yüzde şişlik, anosmi, epifora ve baş ağrısıdır (4). Şikayeti olan hastaların tanı alması yaklaşık 6 ay ile 8 yıl arasında sürebilmektedir (2). Olguda burun tıkanıklığı dışında bir semptom mevcut olmayıp bu şikayetin de septum deviasyonuna bağlı olduğu düşünülmüştür.

Rinolitler genellikle unilateral olmakla birlikte tipik olarak nazal kavite tabanında, maksiller sinüs ile alt konka veya septum ile alt konka arasında bulunur (5). Rinonitler sıklıkla gri, kahverengi veya yeşil-siyah renkte olup çevresinde çoğu zaman ödemli granülasyon dokusu, koagulum ve pürülan sekresyon bulunur.

Rinolitler magnezyum ve kalsiyum tuzlarının çökmesiyle zaman için büyüme eğilimindedir. Komşu kemik yapılarda zaman içinde destrüksiyon gelişebilmektedir. Destrüksiyon genellikle septum ve maksiller sinüs medial duvarında gelişebilmekle birlikte sert damakta perforasyon ve nadir de olsa naso-oral fistüller gelişebilmektedir (6,7). Olgumuzda herhangi bir destrüksiyon bulgusu izlenmedi.

Anterior rinoskopi ve endoskopik nazal bakı çoğu zaman rinolitler için tanı koydurucudur. Şüpheye düşülen olgularda bilgisayarlı tomografinin (BT) kullanılması önerilmektedir (8). Bazı vakalar pürülan akıntıdan dolayı rinosinüzit olarak değerlendirilip, tıbbi tedavi alabilmektedir. Endoskopik bakıda ve BT'de rinolit vakalarına sinüzit, kronik vestibülit, alerjik rinit, septum deviasyonu ve skuamöz hücreli karsinomun eşlik ettiği bildirilmiştir (1).

Rinolitlerin tedavisi rinolitin boyut ve yerleşimlerine göre lokal veya genel anestezi ile total olarak çıkarılmasını içermektedir. Tek taraflı burun tıkanıklığı ve uzun süreli kötü kokulu akıntı şikayeti olan hastalarda rinolit mutlaka akılda tutulması gereken bir öntanı olup olgumuzdaki gibi ek bir şikayeti olmayıp primer septorinoplasti sırasında rastlantısal olarak da saptanabilmektedir.

\section{Kaynaklar}

1. Özdemir S, Akbas Y, Görgülü O, Selçuk T, Sayar C. Rhinolithiasis: Review of 21 cases. Am J Rhinol Allergy 2010;24(6):136-9.

2. Yuca $\mathrm{K}$, Caksen $\mathrm{H}$, Etlik Ö, et al. The importance of rigid nasal endoscopy in the diagnosis and treatment of rhinolithiasis. Auris Nasus Larynx 2006;338:19-22.

3. Tarhan AE, Oğuz H, Şafak MA, Özdek A, Samim E. Rhinolithiazis. KBB BBC Derg 2002;10(2):93-6.

4. Kharoubi S. General review of rhinolithiases. Ann Otolaryngol Cervicofac 2008;125(1):11-7.

5. Sakin YF, Gedik M. Rinolitiyazis: Klinik bulgular, tanı, tedavi ve radyolojik bulgular. Göztepe Tıp Dergisi 2009;24(2):95-100.

6. Bicknell PG. Rhinolith perforating the hard palate. J laryngol Otol 1970;84(11):1161-2.

7. Arora S, Garg LN, Julaha M, Tuli BS. Naso-oral fistula due to rhinolithiasis: A rare presentation. J Oral Sci 2009;51(3):481-3.

8. Hadi U, Ghossaini S, Zaytoun G. Rhinolithiasis: A forgotten entity. Otolaryngol Head Neck Surg 2002;126(1):48-51. 